\title{
Dignity Therapy Led by Nurses or Chaplains for Elderly Cancer Palliative Care Outpatients: Protocol for a Randomized Controlled Trial
}

Sheri Kittelson ${ }^{1}$, MD; Lisa Scarton ${ }^{2}$, RN, PhD; Paige Barker ${ }^{1}$, MD; Joshua Hauser ${ }^{3}$, MD; Sean O'Mahony ${ }^{4}$, MD, MS; Michael Rabow ${ }^{5}$, MD; Marvin Delgado Guay ${ }^{6}$, MD; Tammie E Quest ${ }^{7}, \mathrm{MD}$; Linda Emanuel ${ }^{7}, \mathrm{MD}, \mathrm{PhD}$; George Fitchett $^{8}$, PhD; George Handzo ${ }^{9}$, BCC, CSSBB; Yingewi Yao $^{2}, \mathrm{PhD}$; Harvey Max Chochinov ${ }^{10}$, OC, OM, MD, PhD, FRCPC, FRSC; Diana Wilkie ${ }^{2}, \mathrm{RN}, \mathrm{PhD}$

\footnotetext{
${ }^{1}$ Center for Palliative Care Research and Education, Department of Medicine, University of Florida, Gainesville, FL, United States

${ }^{2}$ Center for Palliative Care Research and Education, College of Nursing, University of Florida, Gainesville, FL, United States

${ }^{3}$ Buehler Center on Aging, Health and Society, Palliative Care, Northwestern Feinberg School of Medicine, Chicago, IL, United States

${ }^{4}$ Palliative Medicine, Rush University Medical Center, Chicago, IL, United States

${ }^{5}$ Helen Diller Family Comprehensive Cancer Center, Center for Educaiton in Palliative Care, University of California, San Francisco, San Francisco, CA, United States

${ }^{6}$ Department of Palliative, Rehabilitation, and Integrative Medicine, The University of Texas MD Anderson Cancer Center, University of Texas, MD Anderson, Houson, TX, United States

${ }^{7}$ Buehler Center on Aging, Heatlh and Society, Northwestern Feinberg School of Medicine, Chicago, IL, United States

${ }^{8}$ Department of Religion, Health and Human Values, Rush University Medical Center, Chicago, IL, United States

${ }^{9}$ Health Services Research \& Quality, HealthCare Chaplaincy Network, Caring for the Human Spirit TM, New York, NY, United States

${ }^{10}$ Research Institute of Oncology and Hematology, Cancer Care Manitoba, University of Manitoba, Winnipeg, MB, Canada
}

\section{Corresponding Author:}

Sheri Kittelson, MD

Center for Palliative Care Research and Education

Department of Medicine

University of Florida

PO Box 100283

Gainesville, FL,

United States

Phone: 13039298452

Fax: 13522650379

Email: skitte@ufl.edu

\begin{abstract}
Background: Our goal is to improve psychosocial and spiritual care outcomes for elderly patients with cancer by optimizing an intervention focused on dignity conservation tasks such as settling relationships, sharing words of love, and preparing a legacy document. These tasks are central needs for elderly patients with cancer. Dignity therapy (DT) has clear feasibility but inconsistent efficacy. DT could be led by nurses or chaplains, the 2 disciplines within palliative care that may be most available to provide this intervention; however, it remains unclear how best it can work in real-life settings.

Objective: We propose a randomized clinical trial whose aims are to (1) compare groups receiving usual palliative care for elderly patients with cancer or usual palliative care with DT for effects on (a) patient outcomes (dignity impact, existential tasks, and cancer prognosis awareness); and (b) processes of delivering palliative spiritual care services (satisfaction and unmet spiritual needs); and (2) explore the influence of physical symptoms and spiritual distress on the outcome effects (dignity impact and existential tasks) of usual palliative care and nurse- or chaplain-led DT. We hypothesize that, controlling for pretest scores, each of the DT groups will have higher scores on the dignity impact and existential task measures than the usual care group; each of the DT groups will have better peaceful awareness and treatment preference more consistent with their cancer prognosis than the usual care group. We also hypothesize that physical symptoms and spiritual distress will significantly affect intervention effects.
\end{abstract}


Methods: We are conducting a 3-arm, pre- and posttest, randomized, controlled 4-step, stepped-wedge design to compare the effects of usual outpatient palliative care and usual outpatient palliative care along with either nurse- or chaplain-led DT on patient outcomes (dignity impact, existential tasks, and cancer prognosis awareness). We will include 560 elderly patients with cancer from 6 outpatient palliative care services across the United States. Using multilevel analysis with site, provider (nurse, chaplain), and time (step) included in the model, we will compare usual care and DT groups for effects on patient outcomes and spiritual care processes and determine the moderating effects of physical symptoms and spiritual distress.

Results: The funding was obtained in 2016, with participant enrollment starting in 2017. Results are expected in 2021.

Conclusions: This rigorous trial of DT will constitute a landmark step in palliative care and spiritual health services research for elderly cancer patients.

Trial Registration: ClinicalTrials.gov NCT03209440; https://clinicaltrials.gov/ct2/show/NCT03209440

International Registered Report Identifier (IRRID)： DERR1-10.2196/12213

(JMIR Res Protoc 2019;8(4):e12213) doi: 10.2196/12213

\section{KEYWORDS}

palliative care; cancer; elderly, religion, therapy

\section{Introduction}

Our long-term goal is to improve spiritual care outcomes for elderly patients with cancer. We will use a spiritual intervention, dignity therapy (DT), to help these patients maintain pride, find spiritual comfort, enhance continuity of self, and ultimately explore meaning in the context of their life-threatening illness. "Dignity Therapy, a novel, brief psychotherapy, provides patients with life threatening and life limiting illnesses an opportunity to speak about things that matter most to them. These recorded conversations form the basis of a generativity document, which patients can bequeath to individuals of their choosing" [1]. However, DT has not been viewed as a spiritual intervention or studied with chaplains as the interventionist. Our thesis is that DT will systematize spiritual care processes and improve patient outcomes (spiritual and cancer prognosis awareness). The spiritual outcomes are important because people with advanced illness report that being at peace with God is as important as freedom from pain [2]. Spiritual concerns are issues for $86 \%$ of patients with advanced cancer [3]. Unfortunately, little research guides interventions for spiritual care. We will address this gap by testing efficacy of DT in a rigorous, multisite, randomized controlled trial (RCT) [4].

Previous studies of DT demonstrated clear feasibility but inconsistent efficacy of DT with virtually no evidence of its mechanism of action. Specifically, the 12 studies of DT ( 8 uncontrolled feasibility and 4 mostly small sample efficacy RCTs) show DT to be an important intervention when delivered by nurses and mental health professionals. Effects on patients' distressing physical or emotional symptoms of life-threatening illness have been inconsistent. Taking a spiritual perspective for reanalysis of data from the 1 large RCT [1], we found that compared with usual care, patients who received DT reported significantly higher dignity impact ratings [5], which is consistent with the DT focus on meaning making, preparation for death, and life-completion tasks. Evidence from our pilot study also suggests that awareness of cancer prognosis outcomes and will-to-live is facilitated by DT [6]. Of the possible explanations for the lack of DT effect on physical symptoms, 1 could be that symptoms only moderate the DT effect, so conceptualizing symptoms as the relevant outcome is mismatched to the operative DT elements. It is also possible that spiritual distress could moderate the DT effect on patients' sense of meaning and purpose [1], which is an important part of dignity impact.

For this study, we selected 2 disciplines of the multidisciplinary palliative care team to focus on spiritual concerns-nurses and chaplains. A nurse-led or chaplain-led DT study of patients receiving outpatient palliative care is needed to determine the efficacy of DT on key spiritual-related patient outcomes (dignity impact, existential tasks, and cancer prognosis awareness) and explore possible moderators (physical symptoms and spiritual distress) of DT's effects on patient outcomes.

We propose a pre- and posttest, RCT with a 4-step (10 months per step), stepped-wedge design [4] to compare effects of usual outpatient palliative care (usual care) and usual care along with either nurse-led or chaplain-led DT on patient outcomes (dignity impact, existential tasks [preparation for death and life completion], and cancer prognosis awareness [peaceful awareness and treatment preferences]). We will assign 6 outpatient palliative care sites to usual care during the first step, and randomly assign 2 sites per step to begin and continue DT led by either a nurse or a chaplain during each of the next 3 steps. During the usual care steps, 280 patients will complete pretest measures (patient outcomes, covariates [physical symptoms and spiritual distress], and satisfaction with palliative spiritual care services), receive usual palliative care, and complete posttest measures (patient outcomes, covariates, and satisfaction). During the experimental steps as part of routine palliative care service delivery, 280 patients will complete pretest measures, receive nurse-led or chaplain-led DT, and complete posttest measures. Using a mixed multilevel analysis with site, provider (nurse and chaplain) and time (step) included in the model, we will compare the usual care and each of the DT groups for effects on dignity impact,existential tasks, and cancer prognosis awareness and explore the moderating effects of physical symptoms and spiritual distress. We will also determine the effect of usual care and DT on the patient's satisfaction with palliative spiritual care services and the patient's unmet spiritual needs. 


\section{Specific Aims}

\section{Aim 1}

We aim to compare usual care and usual care with nurse-led or chaplain-led DT groups for effects on (1)patient outcomes (dignity impact and existential tasks [preparation for death and life completion], cancer prognosis [peaceful awareness and treatment preferences]). We hypothesize that, controlling for pretest scores, each of the DT groups will have higher scores on the dignity impact (primary outcome) and existential tasks (secondary outcome) measures than the usual care group. In addition, patients in each of the DT groups will report better peaceful awareness and treatment preferences more consistent with their cancer prognosis (secondary outcomes) than the usual care group; and (2) processes of delivering palliative spiritual care services (satisfaction and unmet spiritual needs; and secondary outcomes). We hypothesize that each of the DT groups will show increased patient satisfaction with spiritual care services and fewer unmet spiritual needs compared with the usual care group.

\section{Aim 2}

We aim to explore the influence of physical symptoms and spiritual distress on the dignity impact and existential tasks effects of usual palliative care and nurse-led or chaplain-led DT. We hypothesize that physical symptoms and spiritual distress will significantly affect intervention effects. This rigorous trial of DT will constitute a landmark step in gero-oncology palliative care and spiritual health services research.

\section{Research Strategy and Significance}

The proposed palliative care research is responsive to PA-13-354/NOT-CA-14-016, Advancing the Science of Geriatric Palliative Care for Cancer Patients. It is significant for multiple reasons: it breaks new ground in inquiry regarding spiritual care as a part of patient-centered care for elders with serious illness before they get morbidly ill. The study uses an empirically established intervention (DT), opening chaplaincy in palliative care to rigorous health services research. The study advances palliative care research by leveraging a network of collaborators in a recently formed network for large data, and by making use of a relatively novel method, stepped-wedge design that typically reduces sample size needs and makes recruitment more feasible, especially for those who are frail and stressed by their cancer illness and treatments.

\section{Dignity Therapy: An Effective Intervention in Need of More Study}

DT has its conceptual origins in Butler's Life Review [7], which he developed as an antidote to depression in elders and understood as part of a life-cycle task. Both interventions are conceptualized as psychosocial and multidimensional for patient-centered care. But little is known about how DT works and if it can and should be used clinically.

Although DT has been established in RCTs to be beneficial to patients among multiple disease groups in multiple ways, the question of its efficacy when administered in a real-life care setting is not established. Pragmatically, within palliative care teams, it is most likely that nurses or chaplains could include DT as part of their routine work, and we, therefore, have designed a trial to assess the efficacy of DT delivered by nurses or chaplains. Considerations for either discipline include the following facts. In a prior RCT [1], a research nurse administered the DT with significant dignity impact findings. Furthermore, the nursing discipline's focus on holistic care inclusive of spirituality makes this discipline a strong candidate. Although the ratio of nurses to patients is suitable, nurses already have a heavy flow of work that may be sidetracked by DT unless carefully scheduled. In addition, recent work indicates that a taxonomy of chaplaincy activities reasonably aligns with DT components [8,9] and recent findings [10] also indicate that clinicians from nursing and medicine look to board certified chaplains (BCCs) as the professionals with the expertise to provide spiritual care. Chaplain-to-patient ratios and their assignments are not currently suitable for routine offering of DT, but chaplains might be more interested in DT than nurses due to alignment of DT with chaplain tasks. If our findings show that DT led by nurses or chaplains has outcomes better than usual care, in the future, DT could be implemented in many places by redeploying current nursing or chaplain resources, based on their availability. Fortunately, six palliative care outpatient services are committed to test the efficacy of DT led by either nurses or chaplains and thereby provide evidence about the effects of DT compared with usual care in the context of outpatient palliative care of elderly cancer patients.

As palliative care starts earlier in the course of medical therapy and geriatric oncology care continues to seek interventions for ambulatory elders, we have asked if DT can be successfully administered in outpatient settings. The findings from a pilot study conducted in a colorectal cancer clinic indicate feasibility in an outpatient setting [6]. This pilot study provides guidance about where DT should be done and when in the sequence of the patient's clinical encounters. Our experience with this study also helped us plan who should transcribe the interview, how to return the legacy document, and how long an interval between transcription and delivery is suitable. None of these decisions are established for clinical practice, but the proposed study will provide evidence from 6 sites to better inform future clinical practice implementation of DT, including the impact on the flow of the team's work and DT's impact on illness acceptance and cancer care goals. Successful completion of the proposed study is likely to have a significant and sustained impact on gero-oncology care in the future. 
Figure 1. DT_Fig 1_Conceptual Framework.png.

Fig 1. Conceptual Framework.

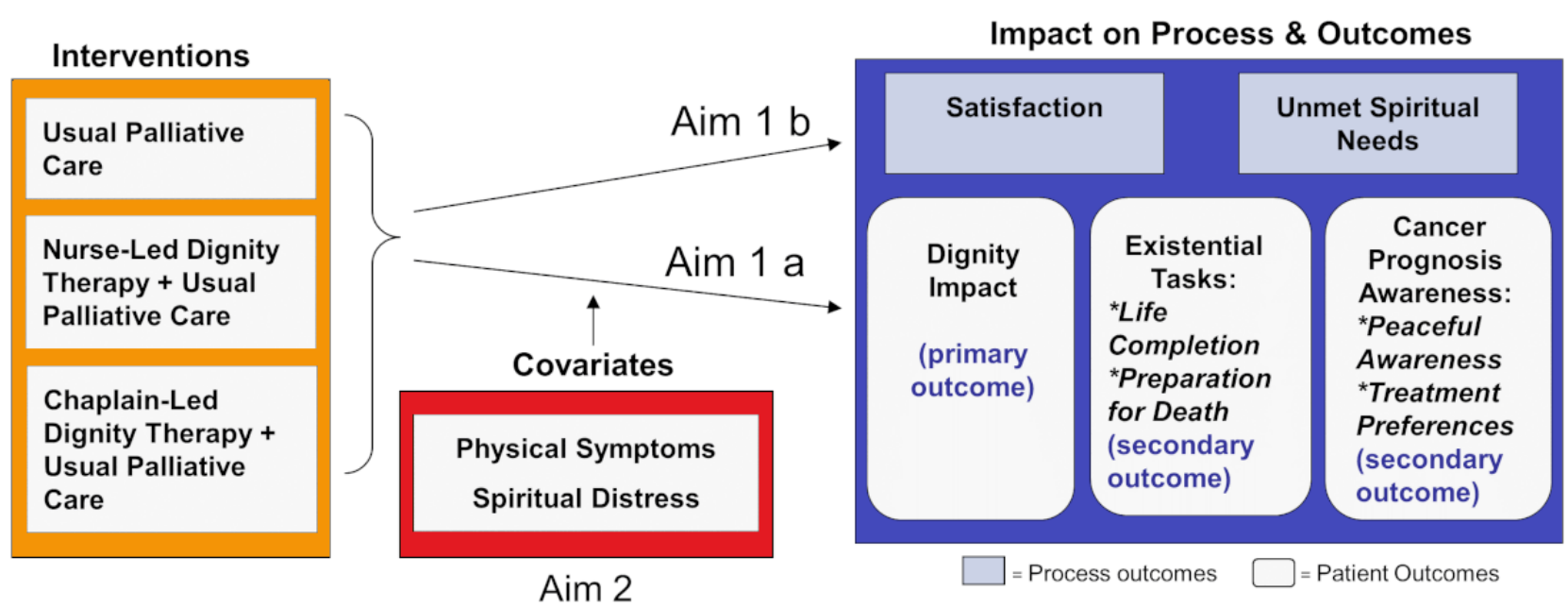

\section{Spiritual Interventions Are Important to Patients but Understudied}

Many elders becomemore spiritually inclined as a life-cycle phenomenon [11,12]. However, little research exists on how this inclination relates to their medical care. New evidence suggests that $D T$ is primarily a spiritual intervention with implications in the other spheres of a person's experience.

Figure 1 displays the study's conceptual framework including the mechanisms to explore. In this individual-level model, we conceptualize physical symptoms and spiritual distress as moderators of the DT effect on spiritual outcomes, measured as dignity impact, existential tasks, and cancer prognosis awareness, and on process measures (patient satisfaction and unmet spiritual needs).

In a study of factors considered important among 340 patients, with advanced illness, most of whom were elderly, some diagnosed with cancer, being at peace with God was as important as freedom from pain [2]. This finding is consistent with the broad consensus that attention to patients' spiritual concerns is 1 of the core dimensions of palliative care and a part of comprehensive geriatrics care [13-15]. Research with terminally ill patients makes clear that, in their view, a good death includes addressing several central spiritual issues and tasks $[2,16]$. A body of evidence is developing that describes moderate to high levels of spiritual concerns, unmet needs, or struggles among patients in palliative care or with advanced illness $[3,17,18]$. Existing evidence is limited but points to improved patient illness experience when patients' spiritual needs are addressed, as well as greater use of hospice rather than ICU care at the end of life [19]. Furthermore, when patients feel that their spiritual needs are unmet, they have lower satisfaction with care and increased emotional distress [20,21].

Delivery of spiritual care services is a variable and the evidence-based studies on chaplaincy interventions are limited. There are few published studies of interventions designed to address the spiritual needs of palliative care patients [22] and no studies of spiritual care provided by chaplains create a gaping hole in knowledge of the effects of the interdisciplinary team. Fortunately, professional chaplaincy is currently undergoing an important transformation. Until now, chaplaincy practice has been guided primarily by tradition and expert opinion. However, professional chaplaincy associations recently embraced the importance of evidence-based care, as have practicing chaplains [23]. Presently, the major obstacle that prevents chaplains from adopting evidence-based practice in palliative care is the absence of any research about chaplains' interventions. Although much of US health care and elsewhere is shifting from a focus on volume-based metrics (eg, number of patients seen or procedures done) to value-based metrics such as increasing patient satisfaction, chaplaincy has been very slow to make this change particularly with regard to proposing and testing appropriate outcomes. In the proposed study, we begin to fill this gap.

Few protocols- or evidence-based chaplaincy interventions have been used to meet the spiritual needs of people facing aging with chronic or serious illness or to test whether meeting those needs would improve outcomes valued by the elderly patient with cancer. Therefore, rigorous evaluation of a manualized, evidence-based intervention would constitute a landmark step in gero-oncology and palliative care research and in nursing and especially chaplaincy health services research. DT is a well-designed, validated, and manualized intervention well-suited for clinical protocolization. For these reasons, we proposed to include both nurse-led and chaplain-led DT with each compared only with usual palliative care and hypothesize that each DT group will report higher dignity impact than their respective usual palliative care group, which would mean that either discipline could lead DT when it is implemented clinically in palliative care. Nurses, but not chaplains, have been the DT interventionists in previous feasibility studies; however, we expect both can be trained to competently lead DT in the outpatient palliative care setting with elderly cancer patients. Distinguishing effects between the DT groups is beyond the scope of our application, but our findings will provide effect size estimates for future studies, should such a comparison be warranted by our findings. Both disciplines need to be included 
in this study to provide an efficient test of the efficacy of DT and time of delivery in clinical care by the disciplines most likely to be available, an important issue for translation of result findings into practice.

\section{Addressing Intrinsic Limitations to Palliative Care Research by Leveraging Our Network and Using Novel Design}

This study is generated from a group of collaborators that came together under the auspices of the Patient-powered Spirituality-and Quality-of-life-focused Advanced-illness Research-network, a group formed in 2013. An open community of 27 organizations (health providers, researchers, patients, and other stakeholders) invited participation in research and health information giving.

Palliative care research is inherently hindered by the patients' severity of illness. High illness burden and short life spans make participant accrual and retention challenging; the participation burden must be minimal. Using a stepped-wedge design, 1 possible design for an RCT [4], will require a smaller number of participants and allow intervention integration into the care process while maintaining power, data quality, and desirable design features including randomization to control and intervention groups.

In summary, successful achievement of study aims will have important impact on the fields of geriatrics, comprehensive cancer care, and palliative care by showing whether DT can be optimally used in routine care settings to bring better illness experience to patients. It will further advance understanding of how DT works.

\section{Innovation}

This proposed work is innovative in 6 ways. First, and most importantly, we primarily conceptualize DT as a spiritual intervention for individuals with serious illness. Other researchers have approached DT as an intervention that broadly improves the dignity of patients nearing the end of life but examined the effects of DT on a variety of outcomes and only psychosocial outcomes showed a significant effect [24,25], In contrast, our second innovation is the use of spiritual outcomes as primary and secondary indicators of the DT effect. Our focused conceptualization of DT as a spiritual intervention leads to our choice of unique outcome measures and DT's focus at the level of the individual patient, though it could be conceptualized at the family level, which is beyond the scope of the proposed study. Other DT researchers used multiple measures of physical and psychological symptoms, as well as a broad measure of personal dignity. In contrast, our measures focus on dignity impact and existential tasks that help patients feel prepared for life completion and to have awareness of their prognosis. Furthermore, our measures of these constructs have been successfully used in previous palliative care or DT-related studies, and our recent reanalysis of RCT data shows that dignity impact differed for the DT group compared with usual care and another patient-centered intervention [5]. Although there is consensus about the central role of spiritual care in palliative care, there are few studies about spiritual care and no studies of spiritual care provided by chaplains. Thus, the third innovation of our study is that it employs a rigorous research design to test the efficacy of a manualized nurse-led or chaplain-led intervention in the palliative care context. Studies such as this are essential to clarify what spiritual care contributes to palliative care and to advance an evidence-based approach to chaplaincy care. Consistent with our rigorous test of a spiritual intervention, our fourth innovation will be to gather detailed information, in both the usual care and DT samples, about the nurses and chaplains' assessments and activities for descriptive purposes. The development of evidence-based chaplaincy has been hampered by the lack of evidence-based assessment instruments and standardized descriptions of chaplaincy care. Our work will employ innovative approaches for nurse or chaplain assessment of the patients' spiritual needs and for nurses' or chaplains' description of the care they provide. Prior studies of DT have focused on its effects on key outcomes and patients' reports of its benefits. They have not proposed or tested hypotheses about the ways that DT improves patient dignity during serious illness like cancer. The fifth innovation is the test of 2 new hypotheses about 2 moderators of DT effects, and we will employ rigorous measures to do so. The sixth innovation is that we will employ a stepped-wedge design, which has been used in other fields, but is new to clinical trials in the palliative care context and addresses the challenges of recruitment in this clinical setting.

In summary, by focusing on DT as a spiritual intervention, using a new conceptual model and measures consistent with the model to examine its effect, examining several pathways that shape its effect, and using a stepped-wedge design, our study will contribute important novelties to palliative care research. In addition, by testing the effects of nurse-led or chaplain-led DT, we will advance an evidence-based approach to spiritual care in the gero-oncology palliative care context, which is highly responsive to the National Institute of Aging's and the National Cancer Institute's request for palliative care applications (PA-13-354/NOT-CA-14-016) to study elderly cancer patients.

\section{Approach}

\section{Study Team}

Our study has a high probability of success because we will apply an interdisciplinary approach with highly productive investigators possessing expertise in palliative medicine, chaplaincy health services research, and nursing research focused on palliative care topics. The multiple principal investigators, MPIs (LE, GF, and DW), and coinvestigators, Co-I (MC, GH, and YY) have worked together within the HealthCare Chaplaincy Network and on palliative care research and publications for many years [26].

\section{Preliminary Studies}

Harvey Chochinov, MD PhD, originator of DT and lead investigator on many of its main studies, is a highly involved member of our team and provided data analysis of the dignity impact measure [5]. In addition, we and other research groups have established its feasibility among seriously ill patients, including those receiving hospice or palliative care. As we recently reviewed [26], 12 studies of DT established it as an important intervention: 8 uncontrolled feasibility studies (3 with 
29 to 100 patients) and 4 efficacy RCTs (3 with less than 65 patients; Table 1). Taken as a group, 2 findings stand out. First, DT does not have consistent effects on distressing physical or emotional symptoms experienced by patients with life-threatening illness. As Hall et al [24] noted, 1 possible explanation for these inconsistent findings is that DT does not directly affect physical symptoms and thus it is a mistake for DT research to focus on physical symptoms or related outcomes as primary success indicators. Second, patients who receive DT provide uniformly high ratings of satisfaction and benefits for themselves and report significantly higher dignity impact ratings than patients who receive usual care or another patient-centered intervention [5]. It is important that all the existing studies consistently show feasibility of DT, and 1 study shows promising evidence that dignity impact is an appropriate outcome [5]. These findings are important as dignity impact is important to patients, especially the elderly with life-threatening illness, such as cancer. In addition, DT increased patients' sense of meaning and purpose and their will to live [27], which is important for patients continuing cancer treatments and participating in cancer research (both are emphases of NOT-CA-14-016).

In summary, we propose conceptualization of DT as a spiritual intervention that assists with the existential tasks faced by elderly patients as they face a serious illness like cancer. This conceptualization leads us to 2 additional decisions. First, nurses and chaplains are the appropriate members of the palliative care team to offer DT. As prior studies had the DT delivered by palliative care nurses or other health professionals, showing that the efficacy of DT is significantly better than usual care, whether the DT is delivered by chaplains or nurses, would be a scientific and clinical advance for translation of DT into geriatric and oncology practice. Second, although they have not been used in prior DT studies, measures of the existential tasks associated with life-threatening illness, as well as dignity impact, are appropriate DT outcome measures.

Although there is limited research about the benefits of chaplains' care [33] and no research about the benefits of chaplains' care in palliative care, for decades chaplains have understood their important role in helping patients with existential tasks associated with serious illness [34]. As part of a project funded by the Templeton Foundation and led by members of our team (Emanuel, Handzo), 6 studies of chaplaincy care have recently been completed and published $[35,36]$; others are being prepared for publication. None of these studies tested the effects of chaplain-led DT on patients' existential preparation for death, but one documents that chaplains are willing and able to use a manualized intervention.
Thus, our proposed work will fill 2 unique gaps in DT research: the effects of DT on important existential tasks associated with serious illness; and chaplains' contributions to improving the care of those patients.

Under MPI Dr LE'S mentorship, Vergo conducted a feasibility study of DT early in the illness course of outpatients with stage IV colorectal cancer receiving second line chemotherapy (Table 1 , study 4) [6]. In addition to outcomes on distress, symptoms, and quality of life; relevant outcomes also included peaceful awareness and treatment preferences. Of patients approached to participate, $88 \%$ did so. The findings suggest not only feasibility of DT during cancer care, but some improved physical and emotional symptoms, increased understanding of the terminal nature of their disease, less aggressive end-of-life goals of care, and increased death acceptance over time $(11 \%$ at baseline; $57 \%$ at 1 month post-DT). These results are suggestive of improved spiritual as well psychological, social, and physical states and give our team recent experience with DT for patients with cancer undergoing active cancer treatments.

Working with Chochinov, we recently reanalyzed data from the study of 441 Canadian, Australian, and US hospice or palliative care patients [1] using the 7-item dignity impact scale we propose as our primary outcome. We found strong internal consistency $(\alpha=.85)$ and that the DT group mean score of 21.4 (SD 5.0) was significantly higher than the usual care group mean 17.7 (SD 5.5, $P<.001$ ) and a patient-centered intervention group mean of 17.9 (SD 4.9, $P<.001$ ) [5]. These preliminary findings provide strong support for our proposed 3-arm efficacy trial because they indicate that the DT affects the dignity impact, not an artifact of the attention provided during individualized therapy because the patient-centered intervention group did not show an effect better than usual care. Our prior studies provide solid evidence that the proposed 3-arm study will be successful: access to an ethnically diverse population of patients with cancer and receiving outpatient palliative care, prior success recruiting and retaining in a DT trial of colorectal cancer during cancer care, a well-tested intervention training program and manualized intervention, fidelity measures, and outcome measures that are robust in detecting the effect of DT. We are now poised to learn if nurse-led or chaplain-led DT is more effective than usual care to improve dignity impact as the primary outcome. Our secondary outcomes were sensitive to other psychosocial interventions [37-39], but have not been used in previous DT RCT studies, which is why we do not propose them as primary outcomes. We also have used the measures for moderator effects. Therefore, our preliminary work is strong and warrants the proposed RCT. 
Table 1. Prior trials of dignity therapy.

\begin{tabular}{|c|c|c|}
\hline Study and sample & Design, measures, and interventionists & Findings \\
\hline \multicolumn{3}{|l|}{ Feasibility studies with $N \geq 15$} \\
\hline $\begin{array}{l}100 \text { Canadian \& Australia terminally } \\
\text { ill[28] }\end{array}$ & $\begin{array}{l}\text { Design: Pre-post trial of dignity therapy (DT); Measures: } \\
\text { Single item screening measures for } 8 \text { factors (depression, } \\
\text { anxiety, suffering, suicide, sense of well-being; } \text { QoL }^{\mathrm{a}} \text {, } \\
\text { ESAS }^{\text {b DTPFQ }} \text { ); Intervention: psychiatrist, psychologist, } \\
\text { and palliative care nurses }\end{array}$ & $\begin{array}{l}\text { Significant improvement in suffering and } \\
\text { depressed mood. High proportions gave } \\
\text { positive evaluation to benefits of DT (eg, } \\
91 \% \text { feel satisfied or highly satisfied with } \\
\text { DT, } 86 \% \text { report DT was helpful or very } \\
\text { helpful) }\end{array}$ \\
\hline $\begin{array}{l}80 \text { Danish cancer patients in hospice or } \\
\text { palliative care [29] }\end{array}$ & $\begin{array}{l}\text { Design: Pre-post trial of DT; follow up after (T1) \& } 1 \text { mo } \\
\text { after (T2); Measures: SISC }{ }^{\text {d }} \text { PDI }^{\text {e }} \text { EORTC QLQ-C15- } \\
\text { PA }^{\text {f }} \text { HADS }{ }^{\mathrm{g}} \text {; PPSv2 }{ }^{\text {h}} \text {; DT PFQ; Intervention: psychologists }\end{array}$ & $\begin{array}{l}\text { No change on any measure at T1 or T2 ex- } \\
\text { cept QoL decreased baseline to T1. At T1 } \\
\text { and T2, positive responses on DTPFQ }\end{array}$ \\
\hline $\begin{array}{l}29 \text { Australian patients with } \mathrm{MND}^{\mathrm{i}} \\
{[30,31]}\end{array}$ & $\begin{array}{l}\text { Design: Pre-post trial of DT; Measures: Hope; FACIT-Sp }{ }^{\mathrm{j}} \text {; } \\
\text { PDI; DT PFQ; ALS }{ }^{\mathrm{k}} \text { measures; Intervention: psychologist }\end{array}$ & $\begin{array}{l}\text { Feasibility and acceptability established. } \\
\text { High satisfaction ( } 93 \%) \text { and helpfulness } \\
\text { (89\%) for DT. Not significant: hope, spiri- } \\
\text { tuality, and dignity. }\end{array}$ \\
\hline $\begin{array}{l}15 \text { US stage IV colon cancer patients, } \\
\text { active cancer treatment [6] }\end{array}$ & $\begin{array}{l}\text { Design: Pre-post trial of DT; follow up after DT (T1) \& } 1 \\
\text { mo after (T2); Measures: ESAS; distress; QoL; peaceful } \\
\text { awareness; advanced care planning; DTPFQ (selected } \\
\text { items) Intervention: palliative care oncologist }\end{array}$ & $\begin{array}{l}\text { Feasibility and acceptability established. } \\
\text { High satisfaction }(100 \%) \text { and helpfulness } \\
(88 \%) \text { for DT. No significant changes in } \\
\text { other study measures. }\end{array}$ \\
\hline \multicolumn{3}{|l|}{ Efficacy studies } \\
\hline $\begin{array}{l}441 \text { Canadian, Australian, \& US hospice } \\
\text { or palliative care[1] }\end{array}$ & $\begin{array}{l}\text { Design } 3 \text { arm RCT: DT vs client-centered vs standard care; } \\
\text { Measures: SISC; ESAS; PDI; QoL- } 2 \text { items; HADS; } \\
\text { FACIT-Sp; DTPFQ; Intervention: psychiatrist, psycholo- } \\
\text { gist, and palliative care nurses }\end{array}$ & $\begin{array}{l}\text { No significant differences on any outcomes. } \\
\text { Reanalysis of dignity impact items: DT } \\
\text { group has significantly higher scores than } \\
\text { standard care }(P<.001) \text { or client-centered } \\
\text { care }(P<.001) \text {. }\end{array}$ \\
\hline 45 UK advanced cancer[24] & $\begin{array}{l}\text { Design RCT: Tx = DT plus usual care; Control=usual care } \\
\text { (Phase II trial for acceptability and estimates of effect } \\
\text { sizes); Measures: Primary: PDI; Secondary: Hope; HADS; } \\
\text { EQ-5D'; palliative-related outcomes (Hearn); DTPFQ; In- } \\
\text { tervention: oncologist }\end{array}$ & $\begin{array}{l}\text { No differences on PDI. No differences on } \\
\text { any secondary outcomes, except higher } \\
\text { hope in group at week } 1(P=.02) \text {. Patients } \\
\text { in the DT group had higher scores on } \\
\text { DTPFQ, some significant. }\end{array}$ \\
\hline 64 UK patients in older care homes[32] & $\begin{array}{l}\text { Design RCT (Phase II trial for potential efficacy, feasibili- } \\
\text { ty): Tx = DT plus usual care; Control = usual care; Mea- } \\
\text { sures: Primary: PDI; Secondary: GDS }{ }^{\mathrm{m}}, \mathrm{HHI}^{\mathrm{n}}, \mathrm{EQ}-5 \mathrm{D} \text {, } \\
\text { Acceptability: DTPFQ ; Intervention: palliative care nurse }\end{array}$ & $\begin{array}{l}\text { No differences on efficacy outcomes; re- } \\
\text { duced dignity-related distress on DTPFQ } \\
\text { across both groups }(P=.03) \text {. DT group sig- } \\
\text { nificantly more likely to feel DT had made } \\
\text { life more meaningful at follow up } 1(P=.04) \text {. }\end{array}$ \\
\hline 60 Portuguese terminally ill[25] & $\begin{array}{l}\text { Design RCT: } \mathrm{Tx}=\mathrm{DT}+\text { usual care; Control = usual care; } \\
\text { Measures: HADS; Intervention: palliative care physician }\end{array}$ & $\begin{array}{l}\text { DT associated with lower depression and } \\
\text { anxiety (day } 4 \text { and } 15 \text {, not day } 30 \text {; all } \\
P<.05 \text { ) }\end{array}$ \\
\hline
\end{tabular}

${ }^{\mathrm{a} Q o L:}$ quality of life.

${ }^{b}$ ESAS: Edmonton System Assessment Scale.

${ }^{\mathrm{c}} \mathrm{DTPFQ}=\mathrm{DT}$ patient feedback questionnaire.

${ }^{\mathrm{d}}$ SISC: Structured Interview for Symptoms and Concerns.

${ }^{\mathrm{e}} \mathrm{PDI}$ : Personal Dignity Inventory.

${ }^{f}$ EORTC QLQ-C15-PA: European Organization for Research in Cancer Quality of Life Questionnaire-C15-Palliative.

${ }^{\mathrm{g}}$ HADS: Hospital Anxiety Depression Scale.

${ }^{\mathrm{h}}$ PPSv2: Palliative Performance Scale.

${ }^{\mathrm{i}} \mathrm{MND}$ : motor neurone disease.

${ }^{\mathrm{j}} \mathrm{EQ}-5 \mathrm{D}$ : EuroQol group's five dimensions.

${ }^{k}$ FACIT-Sp: Functional Assessment of Chronic Illness Therapy-Spiritual Well-being.

${ }^{1}$ ALS: amyotrophic lateral sclerosis.

${ }^{\mathrm{m}}$ GDS: Geriatric Depression Scale.

${ }^{n}$ HHI: Herth Hope Index. 


\section{Methods}

\section{Design}

We propose a 6-site, pre- and posttest, randomized, controlled 4-step, stepped-wedge design to compare the effects of usual outpatient palliative care and usual outpatient palliative care along with nurse-led or chaplain-led DT on patient outcomes and palliative care processes. We will assign the 6 sites to usual care during the first-step period (10 months), and randomly assign 2 sites per step to begin and continue DT during each of the next 3 steps (10 months each). Figure 2 shows the stepped-wedge study design with projected numbers of completed patients needed per site, step period, and group (usual care, DT led by either a nurse or a chaplain). Dr. Yao, a highly qualified statistician, will conduct the randomization of site from steps 2 to 4 . Each step will be 10 months long, with DT training during a 1 -week period between steps. For each site and step, a quota of $50 \%$ of the participants will report low or high distress on the Personal Dignity Inventory to assure that we recruit a sample with a range of problems threatening their dignity. Each patient will participate for 4 to 6 weeks. During the 10 months at each step, we expect 23 to 24 patients to participate at each site (93 to 94 total patients per site).

\section{Setting}

For this efficacy study, the settings will include Northwestern University Hospital, Rush University Medical Center, MD Anderson Cancer Center, Emory University, University of California San Francisco, and University of Florida Health. The clinical resources of each of these settings are strong. Our team members have extensive experience recruiting and retaining elderly patients with cancer for studies, including palliative care and chaplaincy research.

\section{Sample}

We will recruit the study sample from the populations receiving care at settings across the United States. For the patients who meet the eligibility criteria, we anticipate a $50 \%$ to $60 \%$ enrollment rate and a $20 \%$ to $30 \%$ attrition rate. We based these estimated numbers on accruals, withdrawals, and deaths in previous palliative care studies conducted at study settings and those in prior studies of DT. During the 40 months devoted to data collection, we anticipated a total available population of
3126 from the outpatient palliative care services of the 6 sites. From this sample, 560 patients will complete sufficient data for the planned analysis, 140 per each of 2 DT groups and 280 total control group. Therefore, we expect each of the 6 sites to complete at least 2 to 3 patients per month and a final total of 93 to 94 patients per site with data for analysis. On the basis of ethnic and racial distribution of patients served at the 6 sites, we expect the final sample to be $50 \%$ female, about $3 \%$ Asian American, 21\% African American, 73\% Caucasian, and 3\% unknown race and $8 \%$ Hispanic ethnicity, representing substantial cultural diversity for this study of DT.

\section{Eligibility Criteria}

Inclusion criteria for study participation require that the patient (1) has a cancer diagnosis (receiving cancer therapy or cancer control care to be responsive to NOT-CA-14-016), (2) is receiving outpatient palliative care, (3) is aged 55 years or older (responsive to PAR-13-354), (4) is able to speak and read English, and (5) is physically able to complete the study (Palliative Performance Scale [PPS] $>50$ [40-45], suggesting a mean in life expectancy of greater than 53 days at the time of enrollment) [45]. Patients will be excluded if they: (1) are legally blind, (2) are cognitively unable to complete study measures (Mini Mental Status Exam [MMSE] <24), (3) have history of psychosis (medical record review), (4) have a Patient Dignity Inventory (PDI) or Religious and Spiritual Struggles Scale score that indicates their distress level falls outside the remaining quota for a given step; quota is $50 \%$ of sample, site, and step with low distress $(\leq 2$ problems rated $>2)$ and $50 \%$ with high distress ( $\geq 3$ problems rated $>2$ or 1 rated $>3$ ), or (5) are enrolled in another intervention study that is focused on concepts similar to the proposed study.

\section{Retention Strategies}

Retention strategies are vital to engaging participants as active research partners. Researchers in this study will always use respectful, empathic communication and schedule data collection at convenient times for participants. We will collect multiple contact information (email, cell phone, home, and extended family phone) to maximize our ability to contact them for final appointments. We also will offer a total of US \$50 per patient to cover time and travel expenses to complete the study measures. 
Figure 2. Stepped Wedge Design.

\begin{tabular}{|c|c|c|c|c|c|}
\hline \multicolumn{2}{|c|}{ Figure 2. Stepped-wedge design } & \multicolumn{3}{|c|}{$\mathbf{N}$ per step per site } & \multirow{2}{*}{$\begin{array}{l}\text { Total N } \\
93\end{array}$} \\
\hline Site 6 & 23 & 23 & 23 & 24 & \\
\hline Site 5 & 23 & 23 & 23 & 24 & 93 \\
\hline Site 4 & 24 & 23 & 23 & 24 & 94 \\
\hline Site 3 & 24 & 23 & 23 & 24 & 94 \\
\hline Site 2 & 24 & 23 & 23 & 23 & 93 \\
\hline Site 1 & 24 & 23 & 23 & 23 & 93 \\
\hline $\begin{array}{l}\text { Step } \\
\text { Patients/ }\end{array}$ & 1 & 2 & 3 & 4 & \\
\hline Step Period & 142 & 138 & 138 & 142 & 560 \\
\hline Usual Care & & & & & 280 \\
\hline Nurse-Led DT & & & & & 140 \\
\hline Chaplain-Led DT & & & & & 140 \\
\hline Step Period Duration (mo) & 10 & 10 & 10 & 10 & 40 \\
\hline
\end{tabular}

\section{Sample Power}

Aim 1 focuses on whether DT has an effect on patient outcomes and palliative spiritual care processes. For the 4-step, stepped-wedge design and the sample size of 23 to 24 patients per site per step (93 to 94 total), we determined from the minimum intervention effect size that the proposed study has at least $80 \%$ power to detect given a 2 -sided significance level of .5. This minimum detectable effect size depends on disparity between sites as indexed by the intraclass correlation (ICC). With no site disparity ( $\mathrm{ICC}=0$ ), we can detect an effect size of 0.5 or above for either the nurse-led or chaplain-led DT intervention; with a more severe disparity ( $\mathrm{ICC}=.4$ ), we can detect an effect size of 0.6 or above. The primary outcome for this study is the 7-item Dignity Impact scale. Using Dignity Impact scale data from the preliminary study [1], the effect size of DT (relative to usual care) was 0.7 [5]. Therefore, we expect this study to have sufficient power to detect the intervention effect on the primary outcome. We do not have preliminary DT data on the secondary outcome measures; however, based on other psychosocial interventions with the measures [37-39,46], our power analysis indicates that as long as the intervention effect on these outcomes is of medium size ( 0.5 as defined by Cohen) or larger, they can be detected in the proposed study. Our study aims to focus on differences between the control group and each DT group, but do not focus on differences between the provider groups because, with the proposed sample, the effect size difference between the nurse-led and chaplain-led DT groups needs to be large $(0.7$ when ICC $=0$ and 0.9 when $I C C=.4$ ) to be detectable (with $80 \%$ power). As prior research shows an effect size of 0.7 between control and DT groups, it is highly unlikely that there will be a significant difference between the provider groups with the proposed sample. Aim 2 seeks to explore whether or not patient distress (physical or spiritual) moderates the effect of the intervention. The intervention effect size of patients with high distress will be compared with that of patients with low distress level. The study has power $(80 \%)$ to detect an effect size difference of 1.0 if there is no site disparity ( $\mathrm{ICC}=0$ ) and 1.3 if there is severe site disparity (ICC $=.4)$. Assuming an average effect size of 0.8 and group balance, we can detect a moderation effect if the intervention effect size for the less receptive group is 0.15 or lower.

\section{Procedures}

Figure 3 shows the general flow of patients through the outpatient palliative care clinics and study procedures for this study of nurse-led or chaplain-led DT over 4 to 6 weeks. Before participant recruitment, the research assistants (RAs) will be trained in all study procedures. The investigators will introduce the study to the palliative care team members. Members of the palliative care team will refer patients to the RA on the day the patient is seen in the palliative care clinic.

The RA will recruit and consent the patient for screening. For those eligible, the RA will provide informed consent and schedule time before the next clinic visit for the patient to complete the pretest self-report measures using a tablet with smart pen. Then, the RA will inform the nurse and chaplain that the patient is available for care (usual care or DT, depending on the study step and site). The nurse or chaplain will provide the designated care on the same day as the pretest data collection. When the nurse or chaplain sessions are completed, the nurse or chaplain will inform the RA that he or she has completed all nurse or chaplain sessions. Either in-person if the patient has a clinic visit or by telephone contact, the RA will schedule the follow-up appointment and complete the posttest measures within 5 to 10 days. Upon completion of posttest measures, the RA will provide a US $\$ 50$ cash per card to the patient for time and travel expenses to complete study measures. 
Figure 3. DT Study Flow.

\section{Figure 3. Flow Diagram.}

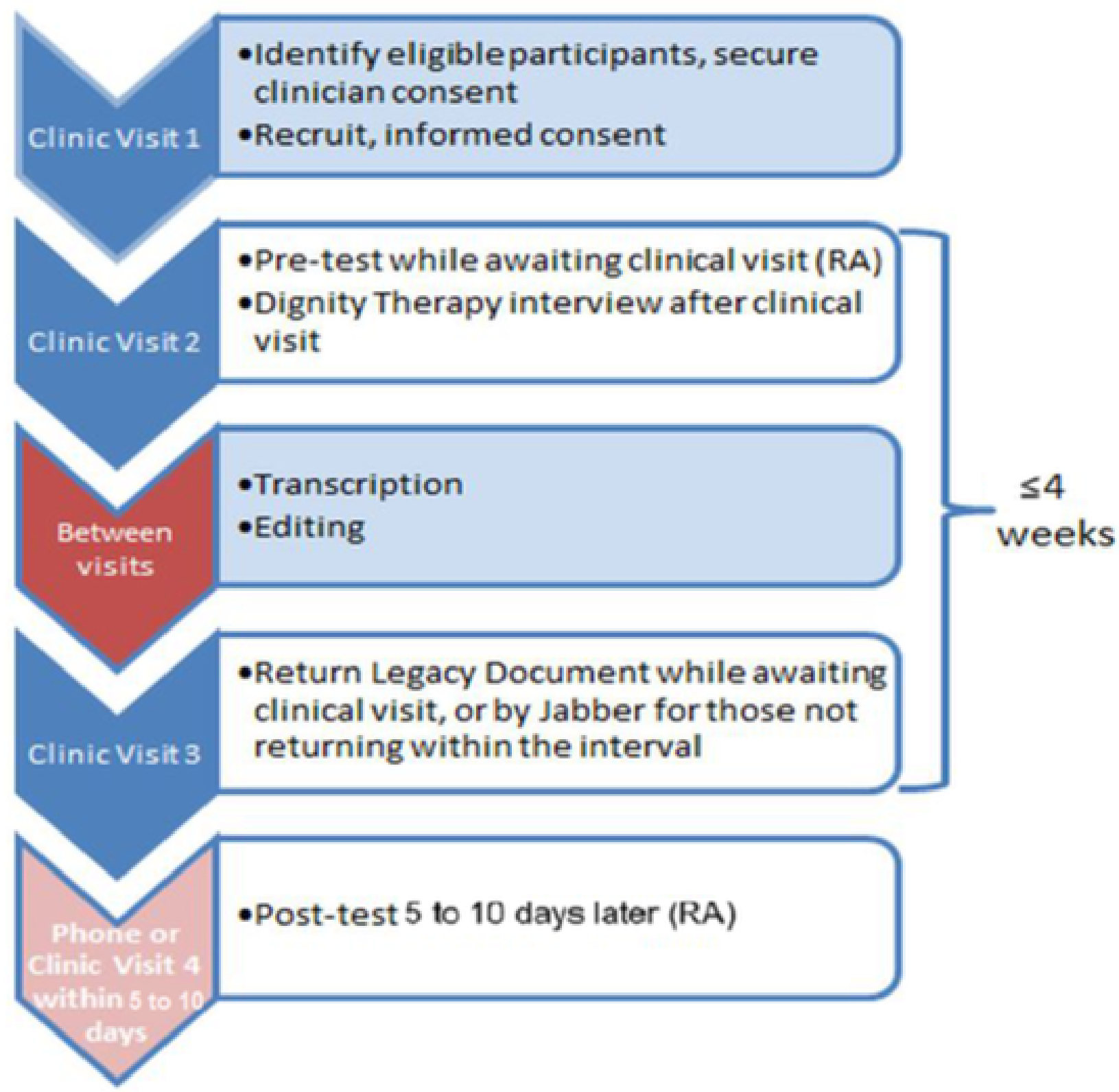


Textbox 1. Examples of the Dignity Therapy Question Protocol.

1. Tell me about your life history; particularly the parts that you either remember most or think are the most important? When did you feel most alive?

2. Are there specific things that you would want your family to know about you, and are there particular things you would want them to remember?

3. What are the most important roles you have played in life (family roles, vocational roles, community service roles, etc)? Why were they so important to you, and what do you think you accomplished in those roles?

4. What are your most important accomplishments, and what do you feel most proud of?

5. What are your hopes and dreams for your loved ones?

6. What have you learned about life that you would want to pass along to others?

7. What advice or words of guidance would you wish to pass along to your [son, daughter, husband, wife, parents, other(s)]?

8. Are there particular things that you feel still need to be said to your loved ones, or things that you would want to take the time to say once again?

9. Are there words or perhaps even instructions you would like to offer your family, in order to provide help to prepare them for the future?

10. In creating this permanent record, are their other things that you would like included?

\section{Interventions}

In this trial, we will compare the efficacy of 2 interventions, both provided either by palliative care nurses or chaplains. The nurses will be the registered nurses who are trained and working with the palliative care team. Chaplains will be BCC. To become a BCC, a person must have completed a graduate-level theological education as well as 1600 hours of supervised practice in an accredited program of clinical pastoral education. BCCs must be in good standing with, and endorsed by, their faith group. In their application for Board Certification and interview, BCC candidates must demonstrate competence in 29 areas. BCC chaplains adhere to a code of ethics that includes "respect for the cultural and religious values of those they serve and refrain from imposing their own values and beliefs on those served." BCCs must complete 50 hours of continuing education annually and a peer review every 5 years [47].

\section{Usual Care}

Palliative care nurses usually see patients each clinic visit to assess vital signs, function, symptoms, and to provide patient and family education. They document findings and interventions in the electronic health record (EHR). Although, usual care for palliative care chaplaincy in the outpatient setting varies by site, chaplaincy care for usual care patients in this study will follow the usual practice.

\section{Dignity Therapy}

The DT intervention is detailed in Chochinov's manualized guide; he serves as a coinvestigator. He advised the development of this application since its inception and gave us permission to use the manualized intervention as it appears here in abbreviated form. The basic questions of the DT interview appear in Textbox 1. The nurse-led or chaplain-led DT intervention involves 3 sessions, each of which follows a set process (Table 2). Nurses are familiar with use of manuals. Chaplain use of manuals is not common, but Dr. Karen Steinhauser (personal communication, February 2014) confirmed that trained chaplains used a manualized intervention guide with high fidelity. Table 3 lists exemplars of the dignity repertoire (perspectives and practices) facilitated by the interview and document preparation process. The standardize approach to the delivery of the intervention facilitates a personal process of reflection and recognition that allows the patient to make meaning of their experience.

\section{Dignity Therapy Training}

Dr. Chochinov, who developed DT, will provide standardized training for the study nurses and chaplains at one of the study sites on 3 separate occasions; each training session will be 2 days in duration. Nurses and chaplains at all sites will be prepared to participate in the DT training during the 3 training dates that will be set early in year 1 but will first occur at the end of year 1. Only those nurses or chaplains at the randomized sites randomized to begin DT at the next step will be trained at any one date, and they will be notified before the training date. By the 4th step, all nurses and chaplains will be trained, assuring competency of all interventionists to deliver DT with fidelity. If there are new nurses or chaplains at a site randomized to the DT step, they will be allowed to attend remaining training sessions. In addition, 2 weeks before the end of each step, the statistician will divulge the 2 sites randomized to the next step. Before training, the MPI will inform the team members about the randomization. To reduce potential influence of the nurse or chaplain anticipating the training and thereby altering usual care practice, we will suspend recruitment, pretest data collection, and intervention delivery during the training periods; posttest data collection will continue.

\section{Intervention Fidelity}

The second RA, who is not involved with data collection, will complete the DT Adherence Form as a measure of intervention fidelity for all DT patients. Members of our team used this tool in previous studies with excellent results. The RA will read each original DT transcript and use this measure to document the nurse's or chaplain's adherence to the DT protocol. Scores range from 0 to 10 , with 10 representing complete adherence. We will monitor the adherence scores to determine if a nurse or chaplain requires additional training by Rev. Handzo (those with scores $<8)$. 
Table 2. Dignity therapy intervention ingredients.

\begin{tabular}{|c|c|c|c|}
\hline Session & Timing & Purpose & Key Ingredients (Features) \\
\hline $\begin{array}{l}\text { First: nurse-led or chaplain- } \\
\text { led Diginity Therapy (DT) } \\
\text { contact (information ses- } \\
\text { sion) }\end{array}$ & Visit 1 & $\begin{array}{l}\text { To establish relationship } \\
\text { with patient; to explain DT } \\
\text { history and procedures }\end{array}$ & $\begin{array}{l}\text { DT is based on piloted studies. Sessions are } \\
\text { tape-recorded, transcribed, edited, and re- } \\
\text { turned to the patient for feedback. Process } \\
\text { is iterative. Purpose is a legacy generating } \\
\text { document for family or friends. DT can be } \\
\text { free form, guided, or both. Guide questions } \\
\text { may be provided before second meeting } \\
\text { upon request. Recording session is sched- } \\
\text { uled. }\end{array}$ \\
\hline $\begin{array}{l}\text { Second nurse-led or chap- } \\
\text { lain-led dt contact (record- } \\
\text { ing session) }\end{array}$ & $\begin{array}{l}\text { Visit } 2:+2 \\
\text { weeks }\end{array}$ & $\begin{array}{l}\text { To provide DT; to record } \\
\text { DT session }\end{array}$ & $\begin{array}{l}\text { Tape-recorded DT session begins with ei- } \\
\text { ther patient directed content or guide ques- } \\
\text { tions. Session takes about } 60 \text { minutes and } \\
\text { is highly flexible, accommodating the pa- } \\
\text { tient's desired discussion content. Nurse or } \\
\text { chaplain takes an active role, forming a } \\
\text { therapeutic alliance while delivering and } \\
\text { organizing the structured intervention. } \\
\text { Legacy document session is scheduled. }\end{array}$ \\
\hline
\end{tabular}

Intermission (No contact) Nonvisit: 2-4 To transcribe the session; to Nurse or chaplain must guide without proweeks edit the manuscript; to revise viding judgment statements. Tape recorder the manuscript; to produce should be tested before session. Recording a legacy document session is transcribed by a professional transcriptionist. Three copies are kept: a) unedited complete transcript, b) 'tracked' version of the edited transcript, and c) final edited version. Single editor initially edits the manuscript: cleaning up the colloquialisms and nonstarter stories, adjusting the chronology, and removing stories that may be hurtful or harmful. Nurse or chaplain reviews the document, making changes with the editor. Final edited manuscript will end with a summary phrase driven by the patient's story.

$\begin{array}{lll}\text { Third nurse-led or chaplain- } & \text { Visit } 3:+4 & \text { To deliver edited legacy } \\ \text { led DT contact (Legacy } & \text { weeks } & \text { document; to receive fee }\end{array}$ document session) back from patient document; to receive feed-

Nurse or chaplain delivers final edited legacy document to the patient. Nurse or chaplain reads it to the patient or the patient will read it alone. Patient may request editorial changes which will be completed within 24 hours. If revisions are necessary, nurse or chaplain makes arrangements for the final delivery of the legacy document within 24 hours. Patient makes arrangements to deliver the legacy document to loved ones.

Nurse or chaplain makes final revisions based on patient feedback and delivers the final legacy document to the patient.
Process Considerations and

Issues

Rapport must be established with patient. Patient must understand the process. Nurse or chaplain should be knowledgeable of process. Nurse or chaplain should have guide questions available for patient.

Nurse or chaplain must maintain respect, empathy, support, and dignity.

Nurse or chaplain read transcription copy for accuracy before editing. Editor must remain unbiased while editing, making sure the themes come through without changing the content. Editor must choose an ending to summarize the patient's story without biasing content. Timeliness is important.

Editing may not satisfy the patient. Theme may not be approved by patient. Patient may not be able to provide feedback

Final revisions are not approved by patient (process closure) 
Table 3. Dignity therapy: exemplars of repertoire (perspectives and practices) facilitated by interview and document preparation process.

\begin{tabular}{|c|c|}
\hline Dignity conserving Repertoire & Ways of looking at one's situation, or personal actions that can bolster or reinforce a sense of dignity \\
\hline Dignity conserving perspectives & Internally held qualities, often based on long standing personal characteristics, attributes, or world view \\
\hline Continuity of self & A sense that the essence of who one is continues to remain intact, in spite of one's advancing illness \\
\hline Role preservation & Ability to continue to function in usual roles to maintain a sense congruence with prior views of self \\
\hline Generativity and legacy & The solace and comfort in knowing that something lasting will transcend their death \\
\hline Maintenance of pride & The ability to maintain a positive sense of self regard or respect \\
\hline Hopefulness & An ability to see life as enduring, or having sustained meaning or purpose \\
\hline Autonomy and control & A sense of control over one's life circumstances \\
\hline Acceptance & The internal process of resigning one's self to changing life circumstances \\
\hline Resilience or fighting Spirit & Mental determination to overcome illness-related concerns and optimize quality of life \\
\hline Dignity conserving practices & Variety of personal approaches or techniques that patients use to bolster or maintain their sense of dignity \\
\hline Living in the moment & Focusing on immediate issues in the service of not worrying about the future \\
\hline Maintaining normalcy & Continuous or routine behaviors, which help individuals manage day-to-day challenges \\
\hline Seeking spiritual comfort & Turning toward or finding solace in one's religious or spiritual belief system \\
\hline
\end{tabular}

\section{Measures}

All our measures have been used among palliative care populations, summary of timing of these measures is shown in Table 4. To collect these data, we will create a REDCap study site using the UF REDCap system, which the UF CTI supports and makes available for NIH funded studies without cost. All data collection sites will use this secure data collection site. Patients will use a tablet with a smart pen to enter the data into the REDCap system. Wilkie et al are successfully using this cost-effective approach to data collection for another palliative care study [48] focused on African American caregivers and the data manager is well versed with REDCap and current mobile devices. Wilkie et al is also successfully using mobile tablet or pen devices in a study of hospice patients in their homes and replicating prior findings of the clear feasibility of elderly patients with cancer near the end of their lives using the tablet technology, especially with use of a smart pen device [49]. We expect that patients will take 30 to 45 minutes to complete the measures at pretest and 15 to 20 minutes at posttest.

\section{Patient Outcomes}

The primary study outcome is dignity impact with all study measures. The secondary outcomes are existential tasks and cancer prognosis awareness.

\section{Dignity Impact}

Our primary outcome measure is a 7-item Dignity Impact Scale [5]. We took the items from the DT Patient Feedback Questionnaire that has been used in a number of studies of DT [50]. The 7 items addressed the concept of DT and showed significant differences between those who received DT and those who did not in an RCT [1]. The items have been used in many DT studies with evidence of their validity in the target population. We modified the wording of the items to fit our pretest and posttest study design. A sample item is "The care I received during the past month has increased my sense of dignity." The items are scored on a 5-point scale from "strongly disagree" (1) to "strongly agree" (5). The Cronbach $\alpha$ from a preliminary study was .85 [5]. Scores ranged from 7 to 35 in the DT group and 7 to 29 in the usual care group and showed sensitivity to DT effects at posttest with an effect size of 0.7 [5]; it was not measured at pretest, but we will do so to increase power and potential for inferences.

\section{Existential Tasks}

The existential tasks of importance in the proposed study are preparation for death and life completion. Our measures of preparation and completion are taken from the QUAL-E, a measure designed to evaluate the quality of life at the end of life and to assess the effectiveness of interventions targeted to improve the quality of life at the end of life [46]. The 4-item Preparation subscale assesses an individual's sense of integrity and concerns about being a burden to significant others. A sample item is "I have regrets about the way I have lived my life." The 7-item Completion subscale assesses an individual's sense of meaning and peace, as well as any unfinished interpersonal business. A sample item is "I have been able to share important things with my family." The items are rated on a 5-point scale from "not at all true for me" (1) to "completely true for me" (5). The items in the Preparation subscale are reverse scored. The Preparation and Completion scales have demonstrated good reliability and validity [46]. Validity of both measures was shown by correlations in expected directions with other measures of quality of life (FACT-G; Missoula-Vitas QOL) and spiritual well-being (FACIT-Sp). In a diverse sample of 248 patients near the end of life, the Cronbach alphas were .68 and .80 for Preparation and Completion, respectively. The 1-week ICCs for participants with no changes in health status were .73 for Preparation and .72 for Completion. 
Table 4. Measures, time points, and person who completes.

\begin{tabular}{lll}
\hline Measure (concept-aim); [number of items] & Pretest & Posttest \\
\hline Dignity impact (Aim 1) & $\mathrm{X}^{\mathrm{a}}$ & $\mathrm{X}$ \\
Quality of Life at End of Life (QUALE-E) Existential tasks-aim 1) & $\mathrm{X}$ & $\mathrm{X}$ \\
Cancer prognosis awareness (Aim 1) & $\mathrm{X}$ & $\mathrm{X}$ \\
Treatment preferences (Aim 1) & $\mathrm{X}$ & $\mathrm{X}$ \\
Patient satisfaction with chaplain and nurse care (Aim 1) & $\mathrm{X}$ & $\mathrm{X}$ \\
Edmonton symptom assessment scale (physical symptoms-aim 2) & $\mathrm{X}$ & $\mathrm{X}$ \\
Religious and spiritual struggles scale (spiritual distress-aim 2) & $\mathrm{X}$ & $\mathrm{X}$ \\
Demographic and patient characteristics & & - \\
\hline
\end{tabular}

${ }^{\mathrm{a}} \mathrm{X}$ : data collected.

b_: data not collected.

\section{Cancer Prognosis Awareness}

Two measures will provide data for peaceful awareness and treatment preference. Our approach to measuring terminal illness awareness (peaceful awareness) is taken from a study of 280 patients with advanced cancer who participated in the Coping with Cancer Study [51]. In that study, $17.5 \%$ of the sample reported being both peaceful and aware of their prognosis. Peacefully aware patients had lower rates of psychological distress and higher rates of advance care planning than those who were not peacefully aware. Peaceful awareness is also associated with modifiable aspects of medical care (eg, discussions about terminal treatment preferences).

Treatment preferences will be measured with a standardized and validated Hypothetical Advanced Care Planning Scenario that assesses scenario-based goals of care and treatment preferences. This approach, based on work by MPI LE [52], was used successfully in the study of DT in patients with advanced colorectal cancer [6]. Patients will be considered as making "life prolonging" treatment choices if they selected "I want" or "I want treatment tried. If no clear improvement, stop (only for mechanical ventilation)" for either CPR or mechanical breathing. Patients will be considered as making "non-life prolonging" treatment choices if they selected "I do not want" to both CPR and mechanical breathing. Patients selecting "I am undecided" to either CPR or mechanical ventilation and not considered "life-prolonging" in their treatment choices will be categorized as "undecided."

\section{Palliative Care Spiritual Service Processes}

We will measure 2 indicators of palliative care spiritual service processes. They are patient satisfaction with spiritual care and unmet spiritual needs.

\section{Patient Satisfaction}

The items in our 7-item measure of Patient Satisfaction with Nurse or Chaplain Care are taken from the work of 2 leaders in chaplaincy research. VandeCreek [53] developed the 23 item Patient Satisfaction Instrument-Chaplaincy (PSI-C) that he administered to a sample of 1440 patients who had been treated in one of 14 different US hospitals. In their study of patient satisfaction, Flannelly et al [54] used 7 items from VandeCreek's
PSI-C as well as 7 new items they developed. In their study, with 250 patients at 1 hospital, the validity of their items was supported by positive correlations with other items that assessed patients' perception that their spiritual and emotional needs had been met. Following the work of Flannelly et al [54], we will assess 2 aspects of satisfaction; satisfaction with the process of nurse or chaplain care and satisfaction with the impact of the chaplains' care.

\section{Unmet Spiritual Needs}

As clinicians embraced an evidence-based approach to spiritual care, 1 of the challenges they faced is developing instruments that can be used for spiritual assessment [55].

\section{Covariates}

The covariates for this trial include physical symptoms, measured by the revised version of the Edmonton Symptom Assessment Scale (ESAS-r), and spiritual distress, measured by the Religious and Spiritual Struggles Scale as described in the previous section. The ESAS-r is a well-validated and widely used instrument to assess common symptoms (eg, pain, fatigue, loss of appetite, and shortness of breath) in palliative care patients $[56,57]$. Each symptom is rated on a scale ranging from 0 to 10 , where $0=$ no symptom and $10=$ worst possible symptom. The assessment is usually completed by the patient independently. However, the RA will help the patient complete the assessment if he or she is unable to rate all the symptoms.

\section{Descriptive Variables: Characteristics of Patients and Nurse or Chaplain Spiritual Activities}

Via self-report or medical record review, we will collect the patient demographic variables: age, sex, ethnicity, race, education level, marital status, medical diagnoses, health problems, cancer diagnosis date, type, and stage (at diagnosis and at study enrollment), and ongoing cancer treatments (eg, radiation, surgery, chemo, and immunotherapy). We will collect information about the participant's religious and spiritual involvement (eg, religious affiliation and frequency of prayer) using standard items [58].

\section{Screening for Eligibility and Exclusion Criteria}

The PPS, a modified version of the Karnofsky Performance Scale [59], measures 5 functional domains: ambulation, activity 
and evidence of disease, self-care, intake, and level of consciousness. Its scores range in $10 \%$ increments from $0 \%$ to $100 \%$, with a score of $0 \%$ indicating death, $10 \%$ indicating a totally bed-bound patient who is unable to do any activity and needs total assistance, and $100 \%$ indicating the patient is able to carry on normal activity and to work without any special care. The findings from studies conducted around the world and 4 regions of the United States [45] support very strong validity with the KPS [43] and adequate interrater reliability [45]. The PPS has predictive validity for average survival of 53 days at the eligibility score for the proposed study (>50) [40-45]; study participation is 28 to 42 days maximum.

We will use the MMSE for cognitive status screening. The MMSE [60] is a valid and reliable quantitative measure of the patient's cognitive performance and capacity. Rated by the trained RA, it measures on a scale of 0 to 30 a variety of cortical cognitive functions. An MMSE score of 26 to 30 represents a normal range, 20 to 25 represents mild cognitive impairment, and scores below 20 represent moderate to severe impairment. Patients with MMSE scores of <24 [61] will be excluded.

We will use the PDI to assess the level of dignity-related distress in the participants to ensure that a reasonable number of patients experiencing some dignity-related distress are recruited at each step. The PDI contains 25 items that assess a broad spectrum of end-of-life distress including physical, psychological, existential, and spiritual sources of distress [62]. The construct and face validity, test-retest reliability, and factor structure of the PDI have been established [62]. Patients rate each item on a 1 to 5 scale $(1=$ not a problem, $2=$ somewhat of a problem, $3=a$ problem, $4=$ a big problem, and 5=an overwhelming problem). Using a score $>3$ to indicate a problem for that item, 253 patients receiving palliative care reported an average of 5.7 problems (SD 5.5, range 0-24 problems) [63].

\section{Statistical Analysis}

Data management and preliminary data analysis procedures will be supervised by MPI DW and conducted by Dr. YY, the Co-I, and statistician, using statistical software $\mathrm{R}$ version 3.5.2 (R Foundation for Statistical Computing). Data will be stored in a REDCap database and will be exported to R. In the case of missing data, multiple imputations will be used to generate multiple complete datasets on which statistical inference will be performed and then aggregated. Missing at random assumption will be assessed and if necessary sensitivity analysis will be performed using pattern mixture methods. We will consider a $P$ value less than .05 as statistically significant.

Descriptive statistics (ranges, frequencies, means, and SDs) and graphic summary (box plots, histograms, bivariate scatterplots, etc) will be first generated for both patient covariates and outcome measures. We will check patient characteristics to see if there is notable imbalance between the $3 \mathrm{arms}$, as well as whether there are significant variations between sites or over time. Descriptive statistics of patient outcomes and process data will reveal patients' spiritual state, identify potential areas for improvement in nurse and chaplain service, and provide information on nurses' and chaplains' workload both in usual care and when dignity therapy is added and on family related variables (eg, legacy document disposition).

\section{Aim 1}

Linear mixed effects models will be used to compare the effects of usual palliative care with usual palliative care with nurse-led and chaplain-led DT groups on (1) patient outcomes and (2) processes of delivering palliative spiritual care services. Random effects terms will be used to model the variations between sites. A main challenge of data analysis of a stepped-wedge design is the modeling of potential time trends. We plan to treat time as a continuous variable and utilize smoothing splines to model potential time trends. Smoothing splines is a nonparametric method that allows flexibility to model different time trends without overfitting by enforcing a smoothness constraint. Likelihood ratio tests will be used to determine the statistical significance of the intervention effect on various outcome measures. We hypothesize that, controlling for pretest scores, patients in both nurse-led and chaplain-led DT groups will have higher dignity impact scores, higher preparation for death and life completion scores, better peaceful awareness, and treatment preferences more consistent with their cancer prognosis than the usual care groups. We also expect the patients in the DT groups to be more satisfied with the palliative care and have fewer unmet spiritual needs than the usual care groups. We do not expect significant difference between nurse-led and chaplain-led DT interventions. Note that, this does not necessarily mean that the 2 interventions are equally effective. We do not seek to test the equivalence of the 2 intervention arms. At this point, it is premature to speculate on their relative efficacy. We expect most patients in this study to have metastatic cancer. If a sizable portion of our sample has nonmetastatic cancer, we will explore if they respond to DT differently than those with the metastatic disease.

\section{Aim 2}

The effect of physical symptoms and spiritual distress on the dignity impact and existential tasks will be modeled nonparametrically using smoothing splines. Our models will include both main effect for physical symptoms and spiritual distress and their interactions with the intervention. This analysis will provide insight on the type of patients most in need of and most likely to benefit from the DT intervention. Likelihood ratio tests will be used to determine the significance of the interaction. We hypothesize that patients' levels of spiritual distress and physical symptom scores will moderate the intervention effect.

\section{Timeline}

Table 5 presents the basic timeline for general activities to achieve study aims. We will prepare study materials, train, and calibrate staff upon award. DT training will commence at the end of month 15 . The step-up to step2 occurs in month 16 (12 months per step). Data will be collected from months 4 to 54 , processed starting month 4 , analyzed for baseline comparisons starting month 16 and outcomes months 55 to 60 . 
Table 5. Projected timeline for study aims.

\begin{tabular}{|c|c|c|c|c|c|c|c|c|c|}
\hline \multirow[t]{2}{*}{ Study task } & \multicolumn{9}{|c|}{ Study month } \\
\hline & $1-3$ & $4-11$ & $12-19$ & $20-27$ & $28-35$ & $36-43$ & $43-48$ & $49-54$ & $55-60$ \\
\hline Staff preparation & $X^{\mathrm{a}}$ & $-\mathrm{b}$ & - & - & - & - & - & - & - \\
\hline Participant recruitment: $70-142$ patients per year & - & $\mathrm{X}$ & $\mathrm{X}$ & $\mathrm{X}$ & $\mathrm{X}$ & $\mathrm{X}$ & $\mathrm{X}$ & $\mathrm{X}$ & - \\
\hline $\begin{array}{l}\text { DT training for nurses or chaplains (before DT; ongoing } \\
\text { for fidelity) }\end{array}$ & - & - & $\mathrm{X}$ & $\mathrm{X}$ & $\mathrm{X}$ & $\mathrm{X}$ & $\mathrm{X}$ & $\mathrm{X}$ & - \\
\hline Data Processing & - & $\mathrm{X}$ & $\mathrm{X}$ & $\mathrm{X}$ & $\mathrm{X}$ & $\mathrm{X}$ & $\mathrm{X}$ & $X$ & $X$ \\
\hline Data Analysis, reports, and manuscripts & - & - & $\mathrm{X}$ & - & - & - & - & - & $\mathrm{X}$ \\
\hline
\end{tabular}

${ }^{\mathrm{a} X}$ : data collected

$\mathrm{b}_{-:}$not applicable.

\section{Results}

Funding was obtained in 2016 with participant enrollment starting in 2017. Results are expected in 2021.

\section{Discussion}

\section{Potential Problems and Alternate Plans}

This rigorous trial of DT will constitute a landmark step in palliative care and spiritual health services research. We designed this study mindful of a number of threats to study validity as we implement the study within the workflow of outpatient palliative care in 6 sites and present plans to achieve study aims.

\section{Recruitment}

Anticipated numbers of potential participants are based on prior studies among similar patient populations both in in-patient and out-patient settings. However, recruitment is always difficult, especially in palliative care settings. We recruited 6 sites to ensure a generous pool of eligible patients and to use a stepped-wedge design for efficiency in the required sample size. Also, the stepped-wedge design allows flexibility in that, if recruitment proves difficult as proposed, we can add steps and sites to ensure a sufficient sample.

\section{Differences Between Sites}

We include 6 sites and will recruit participants from outpatient services only. We carefully selected sites with consideration of geographic and population diversity, but our analytic model will include random effect terms to account for site differences, should they occur.

\section{Attrition \\ Attrition due to illness burden and death is inevitable in this population. We will monitor attrition carefully throughout the study. If the estimates we have used prove inaccurate we will adjust recruitment numbers accordingly to meet benchmarks throughout the study at each site. We will also analyze data from participants who did not complete the DT to check for differences in patient characteristics and to verify that there is no association between attrition and intervention group assignment.}

\section{Patients Not Returning to Clinic}

Including these patients limits potential loss of patients before they can complete the intervention, for instance, during the interval between the first interview and returning the legacy document. Patients' will be located through the doctor's office or family; those in the hospital at posttest will finish their intervention at the hospital or by phone with electronic or express mail delivery of the legacy document and will still be included in the study. Including these patients will minimize any potential bias. Furthermore, it ensures that the intervention effect size we estimate will reflect the average effect on a realistic patient population, a portion of which will decline in health status before the intervention is complete.

\section{Data Integrity}

We will collect preintervention data using self-report on a tablet with a smart pen. Participant operation of the device may limit data entry, but we will use Dr. Wilkie's extensive expertise in using tablets in the homes of elderly hospice patients with cancer. The RA will be present to assist with data collection if needed. We will track incomplete data patterns and raise the topic at regular study meetings to brainstorm solutions such as an improved user interface or directions. We will collect postintervention data by phone or in-person, if the participant has a clinic visit. Obtaining correct phone information in an era when landlines are rare and patients may not be next to their cell phones may be challenging. We will ask for a backup phone number for this reason. Survey responses by phone may be particularly challenging for our sick population; our training will include protocols for taking a break and repeating questions that allow for the illness burden of our participants.

\section{Availability of Nurses or Chaplains}

Each site has a chaplain available to the palliative care service, but others are available to cover for absences (vacation, illness, etc). Similarly, nurses are available. For each site, at least two interventionists will be trained and immediately replaced by another should there be an absence, resignation, or retirement.

\section{Summary}

We have exceptionally strong research and clinical environments to support the proposed study, and a strong, collaborative, interdisciplinary team distinguished by its rare combination of chaplaincy, nursing, and palliative care researchers. We are 
noted for a history of excellence in palliative care research in elderly cancer patients, including a Templeton Foundation grant to stimulate chaplaincy research in palliative care and several funded R01 level studies focused on palliative care populations. We propose a highly significant and high-quality study in which we will apply rigorous science to an area that sorely needs it: spiritual care research. Studying 560 participants in a pre- and posttest, randomized, controlled 4-step, stepped-wedge design, we will compare the effects of usual outpatient palliative care against the same plus either nurse-led or chaplain-led DT on patient outcomes (dignity impact, existential tasks, and cancer prognosis awareness). Using a multilevel analysis with site, provider (nurse and chaplain), and time (step) in the model, we will determine the efficacy and mechanism of DT when delivered by nurses or chaplains as a spiritual care therapy. Success in this landmark study will yield the first manualized intervention for chaplaincy services, its potential efficacy compared with nurse-led DT, and insights into its mechanisms of action related to spiritual care, an area of great importance to elderly cancer patients receiving palliative care. We will disseminate study findings in a variety of venues for presentation and publication to reach palliative care, oncology, gerontology, chaplaincy, nursing, and other audiences.

\section{Acknowledgments}

This research was made possible by Grant Number 5R01CA200867 from the National Institutes of Health (NIH), National Cancer Institute (NCI) and National Institute of Nursing Research (NINR). Its contents are solely the responsibility of the authors and do not necessarily represent the official views of the NCI or NINR. The final peer-reviewed manuscript is subject to the NIH Public Access Policy. See Multimedia Appendix 1 for NIH review.

\section{Conflicts of Interest}

None declared.

\section{Multimedia Appendix 1}

Untitled.

[PDF File (Adobe PDF File), 165KB-Multimedia Appendix 1]

\section{References}

1. Chochinov HM, Kristjanson LJ, Breitbart W, McClement S, Hack TF, Hassard T, et al. Effect of dignity therapy on distress and end-of-life experience in terminally ill patients: a randomised controlled trial. Lancet Oncol 2011 Aug;12(8):753-762 [FREE Full text] [doi: 10.1016/S1470-2045(11)70153-X] [Medline: 21741309]

2. Steinhauser KE, Christakis NA, Clipp EC, McNeilly M, McIntyre L, Tulsky JA. Factors considered important at the end of life by patients, family, physicians, and other care providers. J Am Med Assoc 2000 Nov 15;284(19):2476-2482. [doi: 10.1001/jama.284.19.2476] [Medline: 11074777]

3. Winkelman WD, Lauderdale K, Balboni MJ, Phelps AC, Peteet JR, Block SD, et al. The relationship of spiritual concerns to the quality of life of advanced cancer patients: preliminary findings. J Palliat Med 2011 Sep;14(9):1022-1028 [FREE Full text] [doi: 10.1089/jpm.2010.0536] [Medline: 21767165]

4. Brown CA, Lilford RJ. The stepped wedge trial design: a systematic review. BMC Med Res Methodol 2006;6:54 [FREE Full text] [doi: 10.1186/1471-2288-6-54] [Medline: 17092344]

5. Scarton L, Oh S, Sylvera A, Lamonge R, Yao Y, Chochinov H, et al. Dignity impact as a primary outcome measure for dignity therapy. Am J Hosp Palliat Care 2018 Nov;35(11):1417-1420. [doi: 10.1177/1049909118777987] [Medline: 29793345]

6. Vergo MT, Nimeiri H, Mulcahy M, Benson A, Emmanuel L. A feasibility study of dignity therapy in patients with stage IV colorectal cancer actively receiving second-line chemotherapy. J Community Support Oncol 2014 Dec;12(12):446-453. [doi: 10.12788/jcso.0096] [Medline: 25866895]

7. Butler RN. The life review: an interpretation of reminiscence in the aged. Psychiatry 2016 Nov 7;26(1):65-76. [doi: 10.1080/00332747.1963.11023339] [Medline: 14017386]

8. Idler E, Perkins M. Impact of hospital-based chaplain support on decision-making during serious illness in a diverse urban palliative care population. 2014 Presented at: Caring for the Human Spirit: Driving the Research Agenda in Spiritual Care in Health Care; March 31-April 3, 2014; New York, NY.

9. Massey K, Barnes M, Summerfeld WT. What do I do? Developing a taxonomy of chaplaincy activities and interventions for spiritual care in ICU palliative care. 2014 Presented at: Caring for the Human Spirit: Driving the Research Agenda in Spiritual Care in Health Care; March 31-April 3, 2014; New York, NY.

10. Balboni MJ, Sullivan A, Amobi A, Phelps AC, Gorman DP, Zollfrank A, et al. Why is spiritual care infrequent at the end of life? Spiritual care perceptions among patients, nurses, and physicians and the role of training. J Clin Oncol 2013 Feb 1;31(4):461-467 [FREE Full text] [doi: 10.1200/JCO.2012.44.6443] [Medline: 23248245] 
11. Idler E. Religion and aging. In: Binstock RH, George LK, Cutler SJ, Hendricks J, Schulz JH, editors. Handbook of Aging and the Social Sciences. Atlanta: Elsevier; 2006:277-300.

12. Wink P, Dillon M. Spiritual development across the adult life course: findings from a longitudinal study. J Adult Dev 2002;9(1):79-94 [FREE Full text] [doi: 10.1023/A:1013833419122]

13. National Quality Forum. National Voluntary Consensus Standards for Palliative Care and End-of-Life Care URL: http:/ /www.qualityforum.org/Projects/Palliative Care and End-of-Life Care.aspx [accessed 2019-02-11] [WebCite Cache ID 767fqa30j]

14. Clinical Practice Guidelines for Quality Palliative Care Third Edition. Pittsburgh, PA: National Consensus Project for Quality Palliative Care; 2013.

15. Puchalski C, Ferrell B, Virani R, Otis-Green S, Baird P, Bull J. Improving the quality of spiritual care as a dimension of palliative care: the report of the Consensus Conference. J Palliat Med Oct 2009;12(10):885-904. [doi: 10.1089/jpm.2009.0142] [Medline: 19807235]

16. Steinhauser K, Clipp E, McNeilly M, Christakis N, McIntyre L, Tulsky J. In search of a good death: observations of patients, families, and providers. Ann Intern Med May 16 2000;132(10):825-832. [doi: 10.7326/0003-4819-132-10-200005160-00011] [Medline: 10819707$]$

17. Mako C, Galek K, Poppito S. Spiritual pain among patients with advanced cancer in palliative care. J Palliat Med Oct 2006;9(5):1106-1113. [doi: 10.1089/jpm.2006.9.1106] [Medline: 17040148]

18. Hui D, de la Cruz M, Thorney S, Parsons H, Delgado-Guay M, Bruera E. The frequency and correlates of spiritual distress among patients with advanced cancer admitted to an acute palliative care unit. Am J Hosp Palliat Care Jun 2011;28(4):264-270. [doi: 10.1177/1049909110385917] [Medline: 21057143 ]

19. Balboni T, Paulk M, Balboni M, Phelps A, Loggers E, Wright A, et al. Provision of spiritual care to patients with advanced cancer: associations with medical care and quality of life near death. J Clin Oncol 2010 Jan 20;28(3):445-452 [FREE Full text] [doi: 10.1200/JCO.2009.24.8005] [Medline: 20008625]

20. Astrow A, Wexler A, Texeira K, He M, Sulmasy D. Is failure to meet spiritual needs associated with cancer patients' perceptions of quality of care and their satisfaction with care? J Clin Oncol 2007 Dec 20;25(36):5753-5757. [doi: 10.1200/JCO.2007.12.4362] [Medline: 18089871]

21. Pearce M, Coan A, Herndon J, Koenig HG, Abernethy AP. Unmet spiritual care needs impact emotional and spiritual well-being in advanced cancer patients. Support Care Cancer 2012 Oct;20(10):2269-2276. [doi: 10.1007/s00520-011-1335-1] [Medline: 22124529]

22. LeMay K, Wilson K. Treatment of existential distress in life threatening illness: a review of manualized interventions. Clin Psychol Rev 2008 Mar;28(3):472-493. [doi: 10.1016/j.cpr.2007.07.013] [Medline: 17804130]

23. Fitchett G, Nieuwsma J, Bates M, Rhodes J, Meador K. Evidence-based chaplaincy care: attitudes and practices in diverse healthcare chaplain samples. J Health Care Chaplain 2014;20(4):144-160. [doi: 10.1080/08854726.2014.949163] [Medline: 25255147]

24. Hall S, Goddard C, Opio D, Speck P, Martin P, Higginson I. A novel approach to enhancing hope in patients with advanced cancer: a randomised phase II trial of dignity therapy. BMJ Support Palliat Care 2011 Dec;1(3):315-321. [doi: 10.1136/bmjspcare-2011-000054] [Medline: 24653477]

25. Julião M, Barbosa A, Oliveira F, Nunes B, vaz Carneiro A. Efficacy of dignity therapy for depression and anxiety in terminally ill patients: early results of a randomized controlled trial. Palliat Support Care 2013 Dec;11(6):481-489. [doi: 10.1017/S1478951512000892] [Medline: 23506744]

26. Fitchett G, Emanuel L, Handzo G, Boyken L, Wilkie DJ. Care of the human spirit and the role of dignity therapy: a systematic review of dignity therapy research. BMC Palliat Care 2015 Mar;14:8 [FREE Full text] [doi: 10.1186/s12904-015-0007-1] [Medline: 25844066]

27. Chochinov H, Hack T, Hassard T, Kristjanson L, McClement S, Harlos M. Understanding the will to live in patients nearing death. Psychosomatics 2005;46(1):7-10. [doi: 10.1176/appi.psy.46.1.7] [Medline: 15765815]

28. Chochinov H, Hack T, Hassard T, Kristjanson L, McClement S, Harlos M. Dignity Therapy: a novel psychotherapeutic intervention for patients near the end of life. J Clin Oncol 2005 Aug 20;23(24):5520-5525. [doi: 10.1200/JCO.2005.08.391] [Medline: 16110012]

29. Houmann L, Chochinov H, Kristjanson L, Petersen M, Groenvold M. A prospective evaluation of Dignity Therapy in advanced cancer patients admitted to palliative care. Palliat Med Dec 2013;28(5):448-458. [doi: 10.1177/0269216313514883] [Medline: 24311296]

30. Bentley B, O'Connor M, Breen L, Kane R. Feasibility, acceptability and potential effectiveness of dignity therapy for family carers of people with motor neurone disease. BMC Palliat Care 2014 Mar 19;13(1):12 [FREE Full text] [doi: 10.1186/1472-684X-13-12] [Medline: 24646211]

31. Bentley B, O'Connor M, Kane R, Breen L. Feasibility, acceptability, and potential effectiveness of dignity therapy for people with motor neurone disease. PLoS One 2014;9(5):e96888. [doi: 10.1371/journal.pone.0096888] [Medline: 24816742]

32. Hall S, Goddard C, Opio D, Speck P, Higginson IJ. Feasibility, acceptability and potential effectiveness of Dignity Therapy for older people in care homes: a phase II randomized controlled trial of a brief palliative care psychotherapy. Palliat Med 2012 Jul;26(5):703-712. [doi: 10.1177/0269216311418145] [Medline: 21859743] 
33. Jankowski KR, Handzo GF, Flannelly KJ. Testing the efficacy of chaplaincy care. J Health Care Chaplain 2011;17(3-4):100-125. [doi: 10.1080/08854726.2011.616166] [Medline: 22029504]

34. Derrickson B. The spiritual work of the dying: a framework and case studies. Hosp J 1996;11(2):11-30. [doi: 10.1080/0742-969X.1996.11882818] [Medline: 8949011]

35. Shields M, Kestenbaum A, Dunn L. Spiritual AIM and the work of the chaplain: a model for assessing spiritual needs and outcomes in relationship. Palliat Support Care 2015 Feb;13(1):75-89. [doi: 10.1017/S1478951513001120] [Medline: 24612751]

36. Massey K, Barnes M, Villines D, Goldstein J, Pierson A, Scherer C. What do I do? Developing a taxonomy of chaplaincy activities and interventions for spiritual care in intensive care unit palliative care. BMC Palliat Care 2015;14:10. [doi: 10.1186/s12904-015-0008-0] [Medline: 25878558]

37. Keall R, Butow P, Steinhauser K, Clayton J. Nurse-facilitated preparation and life completion interventions are acceptable and feasible in the Australian palliative care setting: results from a phase 2 trial. Cancer Nurs May-Jun 2013;36(3):E39-E46. [doi: 10.1097/NCC.0b013e3182664c7a] [Medline: 23047796]

38. Steinhauser K, Alexander S, Byock I, George L, Olsen M, Tulsky J. Do preparation and life completion discussions improve functioning and quality of life in seriously ill patients? Pilot randomized control trial. J Palliat Med Nov 2008;11(9):1234-1240. [doi: 10.1089/jpm.2008.0078] [Medline: 19021487]

39. Wright AA, Zhang B, Ray A, Mack JW, Trice E, Balboni T, et al. Associations between end-of-life discussions, patient mental health, medical care near death, and caregiver bereavement adjustment. J Am Med Assoc 2008 Oct 8;300(14):1665-1673 [FREE Full text] [doi: 10.1001/jama.300.14.1665] [Medline: 18840840]

40. Anderson F, Downing G, Hill J, Casorso L, Lerch N. Palliative performance scale (PPS): a new tool. J Palliat Care 1996;12(1):5-11. [Medline: $\underline{8857241]}$

41. Virik K, Glare P. Validation of the palliative performance scale for inpatients admitted to a palliative care unit in Sydney, Australia. J Pain Symptom Manage 2002;23(6):455-457. [doi: 10.1016/S0885-3924(02)00407-4] [Medline: 12067769]

42. Olajide O, Hanson L, Usher B, Qaqish B, Schwartz R, Bernard S. Validation of the palliative performance scale in the acute tertiary care hospital setting. J Palliat Med 2007;10(1):111-117. [doi: 10.1089/jpm.2006.0125] [Medline: 17298259]

43. Morita T, Tsunoda J, Inoue S, Chihara S. Validity of the palliative performance scale from a survival perspective. J Pain Symptom Manage 1999;18(1):2-3. [doi: 10.1016/S0885-3924(99)00096-2] [Medline: 10439564]

44. Head B, Ritchie CS, Smoot TM. Prognostication in hospice care: can the palliative performance scale help? J Palliat Med 2005 Jun;8(3):492-502. [doi: 10.1089/jpm.2005.8.492] [Medline: 15992190]

45. Weng L, Huang H, Wilkie D, Hoenig N, Suarez M, Marschke M. Predicting survival with the Palliative Performance Scale in a minority-serving hospice and palliative care program. J Pain Symptom Manage 2009;37(4):642-648. [doi: 10.1016/j.jpainsymman.2008.03.023] [Medline: 18823751]

46. Steinhauser K, Clipp E, Bosworth H, McNeilly M, Christakis N, Voils C. Measuring quality of life at the end of life: validation of the QUAL-E. Palliat Support Care 2004;2(1):3-14. [Medline: 16594230]

47. King SD, Fitchett G, Vandenhoek A. Education of chaplains in psycho-oncology. In: Holland JC, Breitbart WS, Jacobsen PB, Loscalzo MJ, McCorkle R, Butow PN, editors. Psycho-oncology. New York: Oxford University Press; 2010.

48. Bonner G. Community-based end-of-life intervention for African American dementia caregivers University of Illinois at Chicago.: National Institute on Aging; 2013. URL: http://nursing.uic.edu/research/ community-based-end-of-life-intervention-for-african-american-dementia-caregivers/ [accessed 2019-02-12] [WebCite Cache ID 767kvtmps]

49. Wilkie D, Kim Y, Suarez M, Dauw C, Stapleton S, Gorman G. Extending computer technology to hospice research: interactive pentablet measurement of symptoms by hospice cancer patients in their homes. J Palliat Med Jul 2009;12(7):599-602. [doi: 10.1089/jpm.2009.0006] [Medline: 19594343]

50. Chochinov H, Hack T, McClement S, Kristjanson L, Harlos M. Dignity in the terminally ill: a developing empirical model. Soc Sci Med 2002 Feb;54(3):433-443. [doi: 10.1016/S0277-9536(01)00084-3] [Medline: 11824919]

51. Ray A, Block S, Friedlander R, Zhang B, Maciejewski P, Prigerson H. Peaceful awareness in patients with advanced cancer. J Palliat Med Dec 2006;9(6):1359-1368. [doi: 10.1089/jpm.2006.9.1359] [Medline: 17187544]

52. Emanuel L, Emanuel E. The Medical Directive. A new comprehensive advance care document. J Am Med Assoc 1989 Jun 9;261(22):3288-3293. [doi: 10.1001/jama.1989.03420220102036] [Medline: 2636851]

53. VandeCreek L. How satisfied are patients with the ministry of chaplains? J Pastoral Care Counsel 2004;58(4):335-342. [doi: 10.1177/154230500405800406] [Medline: 15739871$]$

54. Flannelly K, Oettinger M, Galek K, Braun-Storck A, Kreger R. The correlates of chaplains' effectiveness in meeting the spiritual/religious and emotional needs of patients. J Pastoral Care Counsel 2009;63(1-2):9-1-915. [doi: 10.1177/154230500906300109] [Medline: 20196357]

55. Fitchett G. Next steps for spiritual assessment in health care. In: Cobb M, Puchalski CM, Rumbold B, editors. Oxford Textbook of Spirituality in Healthcare. New York, NY: Oxford University Press; 2012:299-305.

56. Bruera E, Kuehn N, Miller M, Selmser P, Macmillan K. The Edmonton Symptom Assessment System (ESAS): a simple method for the assessment of palliative care patients. J Palliat Care 1991;7(2):6-9. [doi: 10.1037/t07978-000] [Medline: 1714502] 
57. Watanabe S, Nekolaichuk C, Beaumont C. The Edmonton Symptom Assessment System, a proposed tool for distress screening in cancer patients: development and refinement. Psychooncology 2012 Sep;21(9):977-985. [doi: 10.1002/pon.1996] [Medline: 21671304]

58. Fetzer Institute/National Institute on Aging Working Group. Multidimensional Measurement of Religiousness/Spirituality for Use in Health Research. Kalamazoo, Michigan: Fetzer Institute/National Institute on Aging; 1999.

59. Karnofsky D, Abelmann W, Kraver L. Karnofsky performance scale. Cancer 1948;1:634.

60. Folstein M, Folstein S, McHugh P. "Mini-mental state". A practical method for grading the cognitive state of patients for the. J Psychiatr Res 1975 Nov;12(3):189-198. [doi: 10.1016/0022-3956(75)90026-6] [Medline: 1202204]

61. Wilkie D, Berry D, Cain K, Huang H, Mekwa J, Lewis F. Effects of coaching patients with lung cancer to report cancer pain. West J Nurs Res 2010;32(1):23-46. [doi: 10.1177/0193945909348009] [Medline: 20164474]

62. Chochinov H, Hassard T, McClement S, Hack T, Kristjanson L, Harlos M, et al. The patient dignity inventory: a novel way of measuring dignity-related distress in palliative care. J Pain Symptom Manage 2008 Dec;36(6):559-571. [doi: 10.1016/j.jpainsymman.2007.12.018] [Medline: 18579340 ]

63. Chochinov H, Hassard T, McClement S, Hack T, Kristjanson L, Harlos M. The landscape of distress in the terminally ill. J Pain Symptom Manage 2009;38(5):641-649. [doi: 10.1016/j.jpainsymman.2009.04.021] [Medline: 19713069 ]

\author{
Abbreviations \\ BCC: Board Certified Chaplain \\ Co-I: coinvestigators \\ DT: dignity therapy \\ EHR: electronic health record \\ ESAS-r: Edmonton Symptom Assessment Scale \\ ICC: intraclass correlation \\ MMSE: Mini Mental Status Exam \\ MPI: multiple primary investigators \\ NCI: National Cancer Institute \\ NIH: National Institutes of Health \\ NINR: National Institute of Nursing Research \\ PDI: Patient dignity inventory \\ PPS: Palliative Performance Scale \\ PSI-C: Patient Satisfaction Instrument-Chaplaincy \\ RA: research assistants \\ RCT: randomized controlled trial
}

Edited by G Eysenbach; submitted 17.09.18; peer-reviewed by M Stevens, A Waller; comments to author 19.12.18; revised version
received 31.12.18; accepted 31.12.18; published 17.04.19
Please cite as:
Kittelson S, Scarton L, Barker P, Hauser J, O'Mahony S, Rabow M, Delgado Guay M, Quest TE, Emanuel L, Fitchett G, Handzo G,
Yao Y, Chochinov HM, Wilkie D
Dignity Therapy Led by Nurses or Chaplains for Elderly Cancer Palliative Care Outpatients: Protocol for a Randomized Controlled
Trial
JMIR Res Protoc $2019 ; 8(4):$ :e12213
URL: $\underline{\text { https://www.researchprotocols.org/2019/4/e12213/ }}$
doi: $\underline{10.2196 / 12213}$
PMID: $\underline{30994466}$

CSheri Kittelson, Lisa Scarton, Paige Barker, Joshua Hauser, Sean O'Mahony, Michael Rabow, Marvin Delgado Guay, Tammie E Quest, Linda Emanuel, George Fitchett, George Handzo, Yingewi Yao, Harvey Max Chochinov, Diana Wilkie. Originally published in JMIR Research Protocols (http://www.researchprotocols.org), 17.04.2019. This is an open-access article distributed under the terms of the Creative Commons Attribution License (https://creativecommons.org/licenses/by/4.0/), which permits unrestricted use, distribution, and reproduction in any medium, provided the original work, first published in JMIR Research Protocols, is properly cited. The complete bibliographic information, a link to the original publication on http://www.researchprotocols.org, as well as this copyright and license information must be included. 